WellBeing International

WBI Studies Repository

$11-2011$

\title{
Harnessing Opportunities in Non-Animal Asthma Research for a 21st-Century Science
}

Gemma L. Buckland

Humane Society International

Follow this and additional works at: https://www.wellbeingintlstudiesrepository.org/acwp_arte

Part of the Bioethics and Medical Ethics Commons, Laboratory and Basic Science Research Commons, and the Research Methods in Life Sciences Commons

\section{Recommended Citation}

Buckland, G. L. (2011). Harnessing opportunities in non-animal asthma research for a 21 st-century science. Drug discovery today, 16(21), 914-927.

This material is brought to you for free and open access by WellBeing International. It has been accepted for inclusion by an authorized administrator of the WBI Studies Repository. For more information, please contact wbisr-info@wellbeingintl.org.

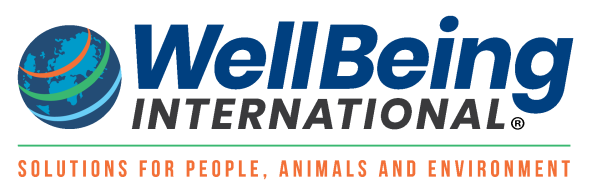




\title{
Harnessing opportunities in non-animal asthma research for a 21st-century science
}

\author{
Gemma L. Buckland, Humane Society International
}

\section{CITATION}

Buckland, G. L. (2011). Harnessing opportunities in non-animal asthma research for a 21st-century science. Drug discovery today, 16(21), 914-927.

\begin{abstract}
The incidence of asthma is on the increase and calls for research are growing, yet asthma is a disease that scientists are still trying to come to grips with. Asthma research has relied heavily on animal use; however, in light of increasingly robust in vitro and computational models and the need to more fully incorporate the 'Three Rs' principles of Replacement, Reduction and Refinement, is it time to reassess the asthma research paradigm? Progress in non-animal research techniques is reaching a level where commitment and integration are necessary. Many scientists believe that progress in this field rests on linking disciplines to make research directly translatable from the bench to the clinic; a '21st-century' scientific approach to address age-old questions.
\end{abstract}

\section{Introduction}

Only two new classes of asthma drug have progressed from the laboratory to the clinic during the past 50 years despite considerable funding and effort [National Centre for the Replacement, Refinement and Reduction of Animals in Research (NC3Rs); http://www.nc3rs.org.uk/news.asp?id51405]. In the meantime, some 300 million people worldwide currently suffer from asthma and it remains the most common chronic disease among children. Although most asthma-related deaths occur in low- and lowermiddle income countries, asthma is a public health problem globally. Approximately one in every 250 deaths worldwide is asthma related, and the incidence continues to increase (WHO; http://www.who.int/mediacentre/factsheets/fs094/en/index.html).

During the past 10 years, the UK Medical Research Council (MRC) alone has provided $£ 35$ million in funding for basic research on asthma (MRC, personal communication). However, a recent call from NC3Rs for 'new experimental models with improved scientific and clinical relevance and reduced reliance on the use of animals' sheds light on the obstacles facing asthma research in the UK (NC3Rs; http://www.nc3rs.org.uk/page.asp?id51231). Recent European Union-funded projects under the Seventh Framework Programme for Research and Technology Development (FP7) have also sought to explore the asthma-environment link (Europa: Cordis; http://cordis.europa.eu). The Innovative Medicines Initiative (IMI), a European project aimed at bringing medicines more quickly to the market, was launched in 2009 and has injected €246 million into research, including asthma. It is hoped that a large patient cohort will enable validation of human biomarkers and development of diagnostic criteria for mechanistic and therapeutic trials (Europa press release; http://europa.eu/rapid/pressReleasesAction.do?reference5IP/ 09/802). The identification of this area as a bottleneck, along with the imbalance of progress and funding, signifies the need to reassess the way that asthma research is carried out and to realign its direction.

Asthma is characterised by airway inflammation, airway hyper-responsiveness (AHR, which is defined by exaggerated airflow obstruction in response to bronchoconstrictors), mucus overproduction, chronic 
eosinophilic inflammation, airway remodelling and episodic airway obstruction [1]. The response of atopic individuals is complex, involving an ordered interplay between mediators, cytokines and cell migrations throughout the respiratory tract, draining lymph nodes and blood. It is now clear that a wide range of environmental factors, superimposed on a genetic back-ground, determine the occurrence and severity of asthma [2]. Although concerted international efforts of scientists and clinicians, the pathobiology of asthma is still relatively poorly under-stood [3].

Epidemiological studies can yield a great deal of information and clinical investigations are powerful tools; however, owing to ethical constraints and regulations surrounding clinical trials since the first mouse models were published in 1994, there has been a general reliance on animal models for asthma studies [3]. During this time, despite gleaning some information on the disease, progress has been slow in elucidating information on the causes, onset, persistence and treatments, owing in part to limitations associated with currently available models $[3,4]$. Despite asthma having originally been discovered as an inflammatory disease through human studies [5], artificially induced animal models of the disease have become increasingly prevalent, in particular murine models. Some investigators have described such models as 'indispensable' from a drug-screening standpoint [6]; whereas others have observed that animal models have intrinsic limitations [3].

The concept of 'personalised medicine' is especially relevant to a disease such as asthma, and the term 'personalised research' has been coined to demonstrate the need for basic research in asthma to reflect the variety of phenotypes that patients present. In many cases, only a reductionist approach is possible; however, complex behaviours of the larger system can be modelled computationally using systems biology tools. With this in mind, there are techniques outside of the mainstream asthma research field that have already shown great promise or that, with some targeted development, could be used to approach the asthma questions from a different angle. In this review, I analyse the current models used in asthma research and highlight the available components that could form part of a change in the way that asthma research is conducted.

\section{The current climate: animal models}

The species of animal most commonly used in asthma research include dogs [3,6], sheep [7] and nonhuman primates (NHPs; principally rhesus and cynomolgus macaques) [8], as well as mice [9], rats [10], cats [11] and guinea pigs [12], with the most prevalent being the murine model. Mouse models have seen a dramatic rise in use over the past decade in an effort to probe the fundamental immunological causes of the disease and to identify and test novel therapeutic strategies [13]. However, in earlier years, rats and larger animal models were more common, having contributed to the identification of potential drug targets: tryptase inhibitors [14], cysteinyl leukotriene receptor antagonists [15] antibodies against interleukin (IL)-5 [16], and the understanding of certain allergic responses in the progression of the disease [17]. However, as illustrated below, there is reason for caution in extrapolating the findings in experimentally induced animal models to the naturally occurring human disease [18].

\section{Modelling a human condition}

Because most animals, with the exception of cats [19] and a very similar condition reported in horses [20], do not spontaneously develop 'asthma' as it is characterised in humans [21], questions inevitably arise when attempting to extrapolate research findings to humans. The pathophysiological differences between humans and various animal species are significant when considering the relevance of experimental data. There are several references detailing different methods for artificially inducing 'asthmatic' reactions in various animal species, which are noteworthy owing to the effects that different methods can have on the 
outcome of research. Among the most common general approaches for asthma induction is sensitising the immune system to a previously unseen antigen and subsequently challenging the airway to the same antigen, because following the cascade of events or a distant outcome that ensues some time after the challenge [3]. A common challenge used with mice [22], rats [23] and guinea pigs [24] is the 'ovalbumin (OVA) protocol', which involves intraperitoneal injection of OVA and an adjuvant (commonly aluminium hydroxide) to prime the immune system [25]. This injection, which can be singular or with a booster injection, is usually followed by an airway challenge of OVA. The resulting immunological response is one similar to asthma and exhibits some of the inflammatory hallmarks. Criticisms of this technique include the use of the adjuvant, which can alter the mechanisms of sensitisation that are being modelled and further distance the animal model from the human condition [3]. In a bid to obviate the need for an adjuvant, sensitisation methods have been developed that expose the immune system to an antigen together with primed or altered $\mathrm{T}$ cells transferred to a naive recipient. Despite being more similar to the human condition, the reaction of this model has been shown to be strain specific in mice, with varying results [26]. Other recognised and more relevant human allergens have also been used in attempts to improve the models, such as house dust mite [27] and cockroach antigens [28], Aspergillus fumigatus [29], ragweed extracts [30] and adjuvants, such as proteases and cigarette smoke [31]. Sensitisation and subsequent challenge with these approaches has resulted in clearly defined T helper 2 (Th2) type responses in the lungs of mice with strain-specific responses, which has enabled genetic, cellular and airway responses mechanism studies [32,33].

It has been suggested that the commonly used mouse models are of limited relevance to the study of juvenile onset asthma [34]; the immune system physiology at birth is very different in mice and humans, and development to an adult state occurs in a matter of weeks in mice versus years in humans [34,35]. The current view of asthma attributes the main effector role to T lymphocytes, specifically Th2 cells, originally identified in mouse studies [17], but also obtained from studies demonstrating an increase in Th2 cytokines in the lungs of patients [36,37]. Differences also exist within species; the most commonly used mouse strains in experimentally induced models differ sharply in their propensity to cytokine production in response to certain agents [35,38]. The BALB/C and C57BL/6 mice differ so much that the choice of model profoundly affects the outcome of the experiment.

NHP models are favoured by some researchers owing to their ability to mount Th2 responses with associated cytokine and chemokine production, alongside airway eosinophilia and increased levels of immunoglobulin ( $\mathrm{Ig}) \mathrm{E}$ similar to that of patients with atopic asthma challenged with the appropriate antigen $[39,40]$. However, NHP models do not demonstrate episodic wheezing, airway obstruction and bronchoconstriction when exposed to atopic stimuli [41]. The influence of stress hormones on allergic disorders and Th2 responses in NHPs have also been documented and should be taken into consideration when reviewing studies involving monkeys [42]. The control over the sensitisation process with NHPs is considered to be one advantage over other models, whereas the requirement for repeated allergen challenge and time and labour constraints are drawbacks [35].

\section{Airway remodeling}

One of the key defining characteristics of asthma is the remodel-ling that occurs within the airways. This process includes subepithelial fibrosis, goblet cell metaplasia and hyperplasia, mucus hypersecretion and thickening of airway smooth muscle [43-47]. The remodelling is thought to be a result of the continued expo-sure to allergen within the airway, which causes repeated inflammatory events [48]. Most mouse models lack these chronic markers of asthma, because they are mostly based on the acute form of the disease [41,49]. With mice, rats and guinea pigs, it has been shown that active sensitisation to an allergen can result in a response but largely on the whole, a continued exposure of the antigen to the 
airway will result in tolerance rather than chronic conditions $[49,50]$ with the exception of some improved studies that have demonstrated chronic remodelling features with repeated allergen exposure [51-53]. These also show promise in inducing a pathology that is similar to human asthma with long-term sensitivity to bronchoconstricting agents.

Ultimately, if the intention of the model is to study and under-stand a chronic pathology, the acute method is inadequate. One example of a different model that has been developed to display long-term AHR is the dog model involving high IgE titre production on ragweed sensitisation [6]. The longevity has been demonstrated for 5 months; however, the approach comes with other disadvantages, such as the labour and costs associated with using dogs as models. Although dogs have a natural predisposition to develop allergic responses to antigens with a clinical relevance to humans, they usually manifest such responses with superficial reactions and the eosinophilia that develops in the airways in response to allergens does not result in an increased responsive-ness for the airways. This is thought to be owing to the larger anatomy of the dog airway [54]. The merits of using different animal models have been reviewed elsewhere $[41,55]$ and, in relation to airway structure, function and physiology, the differences between the available models are substantial. Rat models represent an advantage over mice in being larger in size and are therefore better suited to measure physiological outcomes, such as AHR. With the pronounced IgE and inflammatory response post-sensitisation of the brown Norway rat, the mechanisms driving the asthmatic phenotype can be studied [56]. Models of tolerance in rats enabled the discovery of $T$ regulatory cell importance in suppressing allergic responses [50]. Rats are a preferred model to mice when considering the development of nonspecific AHR. The relative cost and lack of specific probes for larger animal models of asthma has hindered their popularity in the asthma field [3]. Sheep, similar to dogs, are known to mount allergic physiological reposes to certain inhaled allergens in a manner that mirrors the patterns seen in humans: the response to challenge results in an influx of inflammatory cells and mediators into the airway similar to the pattern of variation seen in patients with asthma [7]. Sheep can also demonstrate nonspecific AHR together with similar responses to corticosteroids [7]. However, many drugs that have shown effectiveness in sheep have shown poor efficacy in humans, especially when working through platelet activation factor path-ways [55]. The response to allergen challenge in NHPs closely resembles that of humans in terms of physiology and immunology, and can develop chronic asthmatic phenotypes, such as extensive airway remodelling [57].

\section{Age, genes and environment}

The influence of genetic factors in asthma progression is exemplified with certain individuals being predisposed to a certain phenotype [58]. These genetic factors, combined with environ-mental influences, will determine whether an individual will go on to develop clinical asthma, with the exception of the few late- or adult-onset cases [59,60]. Such events include: viral infection [61], exposure to allergens [62] and other environmental factors, such as pollution and smoking [60], pets [63], bacterial by-products [64] in the in utero environment. The latter illustrates one of the primary limitations of most current animal models: the predominant use of adult animals. It is possible to predispose an animal genetically to develop asthma-like reactions or sensitivity to a specific allergen, and different strains of mice can be used to study heritability of traits typical of patients with asthma, but these are all mechanistically specific and do not enable the multifaceted development of the disease as it presents itself in humans. The substantive immunological differences between juveniles and adults [65], such as signalling deficiencies in infant $\mathrm{T}$ cells, and the process of immunological education with age are often neglected with animal models with only a few neonatal murine studies existing in the literature [66]. The mechanistic limitation of the guinea pig as a model especially for genetic studies is a major drawback of this model. However, there is more agreement between pharmacological responses of guinea pig and human airways than those seen in rodents [41]. There are relatively few studies using NHPs at a young age [40]. 
In addition to the documented immunological differences between mice and humans [67], the cell-specific reactions related to asthma are fundamental to the human form of the disease. Plasma exudation is a key sign of bronchial asthma; the several plasma-derived, inflammatory, repair, leukocyte and growth factor active proteins distribute readily in the human airway [4]. This is not seen in the mouse, even with a heavy allergen overload [34]. The inflammatory cell types also differ: eosinophils in mice accu-mulate readily, yet this distribution is considerably different from humans and, more significantly, the murine eosinophils do not degranulate [68]. Exudation and eosinophil degranulation correlate with disease severity. In addition, rodent mast cells release serotonin, which is not thought to have a role in human asthma [21]. Responses related to target cell secretion of cytokines also differ between mice and humans; IL-3 elicits a stronger response to murine structural cells than to those observed in human airway cells [69]. Likewise, differences between the production and regulation of transforming growth factor (TGF)-b exist between species $[70,71]$. Information is limiting regarding growth factor release and expression in both human asthma and mouse models. However, after a periodic 2-year allergen challenge study in macaques, changes in IgE, airway physiology and eosinophilia consistent with chronic asthma were observed. In particular, IL4, IL5 and IL13 were expressed and corticosteroid treatment was found to be effective on serum histamine levels [57].

Studies involving transgenic mice have underscored the importance of IL-4 [72], IL-5 [73] and IL-13 [74], thought to be key mediators in the Th2-driven allergic response in a large proportion of patients with asthma $[18,41]$. From such studies, several potential therapeutic targets were identified, although in human clinical trials, the efficacy seen in mouse models of asthma could not be replicated [18]. Although mice have been useful for mechanistic studies looking at switching off, suppressing or upregulating single molecular pathways [72,75], transgenic mouse studies are only able to illustrate the importance of a particular mediator or path-way in that particular animal using a specific protocol. When expanding many studies to larger interventions, such as knockout molecules and increasing the range of animal models, it is often the case that the results are not transferrable to the human condition, as is the case with Very Late Antigen-4 (VLA-4), bradykinin, IL-4, and neurokinin studies [76-78]. In total, three studies involving mice have identified airway response targets, have translated to human clinical benefits, for each of these targets substantive human evidence was also available [79].

A further consideration regarding the transgenic animal paradigm is that the pathology of some of the spontaneously developing airway remodelling is more akin to that of chronic lung disease than asthma. Although many of these models enable the consequences of high levels of a particular mediator to be observed, they could in fact be overemphasising the contribution of that particular molecule [80].

\section{Considering anatomy and function}

In addition to interspecies differences at the cellular level, there are also several anatomical differences to consider. The major clinical symptom of asthma in humans is difficulty breathing; this is also the leading cause of morbidity in patients [3]. Breathing difficulties result from restricted air flow, which can occur through airway blockage, constriction or collapse, which could be caused by the thickening of the walls, smooth muscle contraction, inflammatory exudates, and/or alterations in the parenchymal-airway interaction [81,82]. When designing a disease model, these factors should be taken into account, given that the ultimate aim is to mimic human clinical pathology to elucidate the underlying mechanisms. These features have been seen in a selection of cases. Sheep, for example, exhibit bronchoconstriction of the airways both immediately after allergen challenge and nonspecific AHR [83]. Similarly, some mouse [84] and NHP studies show bronchoconstriction [85], whereas cats have also shown airway collapse and 
excessive mucus accumulation [86]. Mice studies have demonstrated smooth muscle mass build up and remodelling in extra bronchial lung vasculature [87], as well as airflow limitation [88]. However, many models also display characteristics that are not present in patients with asthma, such as the lung parenchymal and vascular inflammation and subepithelial deposition of matrix proteins, as seen in mice [3]. Dogs do not demonstrate the asthma-like reactions in the airway, largely attributed to their unique airway anatomy [41].

A significant number of the animals used as models are quadrupeds, which has bearing on the forces acting upon the lungs, owing to gravity and the chest wall [89,90]. Airway branching pattern and morphology also vary among species, which can affect aerosol deposition [91]. For example, an inverse relationship exists between body size and relative airway calibre among rodent species, and mice in particular have a limited proportion of smooth muscle in their airways. Inhalation studies relying on the obligate nasal nature of murine inhalation are already disadvantageous owing to this fundamental difference [91].

The frequency of cell types and receptor classes along the air-ways also differ within and among species and strains [92]. There is no bronchial circulation in mice, which is likely to have an effect on cell migration [93]. The increased ease with which allergic responses can be measured and the similarity in size to the human structure, morphology and function of the airway means that larger animal models perform better than murine models in this regard. The comparative anatomy of small and large animals has been extensively reviewed and highlights that larger animals are more useful to mimic key anatomical and physiological para-meters, such as blood vessel alternations [55,93]. Research techniques will also have a bearing on the results owing to stress caused to animals during experimentation, which can in turn affect physiology and behaviour [94].

With regard to lung function, the varying sizes of the different animal species used in comparison to one another and to humans become an issue $[3,55,95]$. Measuring this parameter in the smaller animal models is technically challenging $[95,96]$. It has become apparent that the most precise techniques are the most invasive, and also represent those furthest removed from natural breathing conditions [96]. By contrast, the technique that monitors breathing in the most natural circumstances bears a significant sacrifice in terms of precision [3]. An example of one of the less invasive technique is noninvasive barometric plethysmography measuring Penh (enhanced pause), which to its disadvantage is highly dependent on breathing frequency. Mice are obligate nose breathers, so the method is affected by upper airway inflammation. Such issues have led to widespread criticism of the method [97]. By contrast, invasive techniques that require anaesthesia, tracheotomy or intubation and mechanical ventilation require care and attention when extrapolating results to humans, and the limitations of these approaches must be recognised [34]. Anaesthesia has been shown to affect asthma mouse models acting at the airway level, lung periphery and also lung pressure readouts [98]. Large animals, such as sheep, dogs, pigs and NHPs have a respiratory capacity similar to small adult humans [3]. When looking at lung function, para-meters such as lung airflow and breathing rates are comparable between humans and sheep, such that procedures that do not require patient cooperation are often carried out on sheep to investigate pulmonary functions in addition to the peripheral airways and bronchial circulation [99]. Airway biopsies and continued lung function testing are possible in large animals and deteriorating lung function can also be analysed for several months $[100,101]$. The wedged bronchoscope technique and forced oscillation technique can be used in dogs and sheep to measure collateral system resistance $[101,102]$ owing to the extensive collateral network of these species, which is absent in mice, pigs and horses [55]; a single animal can also be subjected to different treatments owing to the specificity of the technique, which many scientists prefer because it serves as a refinement method [41]. 
The genetic and physiological similarities shared between NHPs and humans, especially the similarities during postnatal development along with lung function and anatomy likeness, make it easy to carry out pulmonary function measurements with techniques and instruments similar to those used on humans but not requiring consent [40]. Noninvasive forced oscillation is commonly used and provides similar results to those in humans, which is considered more relevant because it does not require anaesthesia [103]. However, the impact of stress on the animal when using this technique has not yet been studied.

Rodent use has dominated in asthma research owing in large part to their small size, low cost, short lifespan and copious pre-existing published data. The relatively higher purchase and maintenance costs together with a less developed understanding of disease mechanisms are issues to consider in regard to large animal models [55,93]. In addition to the legal requirement in Europe outlined in Directive 2010/63/EU [104] and public policy drivers elsewhere, which integrate the principles of the 3Rs [105], there are compelling reasons for refocusing research efforts. Fundamental tenets of Directive 2010/63/EU are that experiments should not be performed if another scientifically satisfactory non-animal method of obtaining the result sought is reasonably and practicably available and that a mandatory contribution to the development of alternative approaches in research, as well as in testing, is required. Given that: (i) animal models do not reproduce all of the main phenotypes of the disease as seen in humans; (ii) the process of interspecies extrapolation is dubious at best and there is urgent need for better translation between the bench and the clinic; and (iii) there are strong ethical and economic drivers pointing to the need for applying the 3Rs in research, it seems prudent to explore the applicability of various non-animal tools and technologies to the asthma research paradigm.

\section{Modelling without animals}

In vitro studies are often cited as lacking the biological complexity of an in vivo system; yet it can also be said that animal models are a 'black box' of sorts that also do not permit a complete understanding of the complex mechanistic interactions within an animal, or the differences between humans and a model species. According to some researchers, the complex mechanisms underlying the genetics of sensitisation and pathophysiology necessitate in vivo studies. They regard the mouse model as a thorough means of replicating the clinical course of disease and long-term effects in the laboratory and contend that in vitro models might not truly reflect the in vivo conditions with systemic mechanisms contributing to responses in the disease state. The lack of models spontaneously developing asthma led researchers to create knockout mice [106] and human-mouse chimeric models [107]; yet there is still much uncertainty surrounding the behaviour of human cells within the mouse infrastructure, and whether allergic or nonallergic asthma is being mimicked. Models produced using different experimental strategies have generated conflicting results, although the reason for the divergence is sometimes unknown, which underscores the need to treat results with caution $[104,108]$. A comparison summary of in vivo and in vitro methods is given in Table 1.

In light of the slow progress achieved using in vivo approaches thus far, the inherent uncertainties of the animal models and the potential benefits of advanced non-animal approaches, such as human patient studies, 3D cell culture systems, computer model-ling and mechanically engineered models [105], one must question whether continued reliance on the animal model is simply a case of remodelling an inadequate model.

Some of the major questions facing asthma researchers today include: how is airway remodelling initiated? Is it related to inflammation or does it represent a separate genetic determinant of asthma? Is airway remodelling reversible? Is it therefore a potential therapeutic target [109]? In the current research climate, each of these questions can be explored in part through in vitro techniques. 
TABLE 1

A summary of asthma research methods

\begin{tabular}{|c|c|c|c|c|}
\hline Methods & Examples & Features & Limitations & Refs \\
\hline $\begin{array}{l}\text { In vivo } \\
\text { models }\end{array}$ & $\begin{array}{l}\text { Mouse } \\
\text { Dog } \\
\text { Sheep } \\
\text { NHP }\end{array}$ & $\begin{array}{l}\text { Complex systems } \\
\text { Multiple variable can be evaluated } \\
\text { Many different models } \\
\text { Small animal models have short lifespan } \\
\text { so disease progression can be studied } \\
\text { Larger animal models share more } \\
\text { similarities with human physiology and lung } \\
\text { anatomy } \\
\text { Transgenic animals offer means of } \\
\text { evaluating genetic effects }\end{array}$ & $\begin{array}{l}\text { Not exact replicas of human disease } \\
\text { Lack genetic heterogeneity } \\
\text { Use of different techniques to } \\
\text { generate transgenesis can lead to } \\
\text { different results } \\
\text { Larger animal model are expensive, } \\
\text { less available and have longer } \\
\text { lifespans } \\
\text { Ethical consideration regarding the } \\
\text { use of animals in science }\end{array}$ & [6-103] \\
\hline $\begin{array}{l}\text { In vitro } \\
\text { cultures }\end{array}$ & $\begin{array}{l}\text { Calu-3 } \\
\text { NHBE } \\
\text { BEAS-2B } \\
\text { 16HBE14-0 } \\
\\
\\
\text { MatTek Epiarway }{ }^{\mathrm{TM}} \\
\text { Epithelix } \\
\text { MucilAir }{ }^{\mathrm{TM}}\end{array}$ & $\begin{array}{l}\text { Long lifespan } \\
\text { Not transformed } \\
\text { Differentiated } \\
\text { Can form cilia } \\
\text { Some secrete mucus } \\
\text { Cytokine secretion } \\
\text { Can express antioxidants } \\
\text { Tight junction formation and multi-layered } \\
\text { Easy access to cells } \\
\text { Primary cells, not transformed (bronchial, } \\
\text { nasal and tracheal origin) } \\
\text { Long life-span (1 month to } 1 \text { year), } \\
\text { differentiated and multi-played } \\
\text { Can form cilia, secrete mucus and forms } \\
\text { tight junctions }\end{array}$ & $\begin{array}{l}\text { Long-term effects cannot be } \\
\text { observed } \\
\text { Interactions with microenvironment } \\
\text { not observed }\end{array}$ & [110-129] \\
\hline $\begin{array}{l}\text { Human } \\
\text { tissue and } \\
\text { organ } \\
\text { explants }\end{array}$ & & $\begin{array}{l}\text { Structure and microenvironment } \\
\text { maintained } \\
\text { Cell interactions can be visualized and } \\
\text { cytokine production, chemokines and } \\
\text { inflammatory effects observed } \\
\text { Can be used in conjunction with other } \\
\text { techniques, such as videomicroscopy }\end{array}$ & $\begin{array}{l}\text { Differences in pathophysiology } \\
\text { between patients } \\
\text { Short lifespan of tissues } \\
\text { Limited accessibility } \\
\\
\text { Ethical considerations } \\
\text { Difficult to study disease } \\
\text { development }\end{array}$ & [130-135] \\
\hline $\begin{array}{l}\text { In silico } \\
\text { modelling }\end{array}$ & $\begin{array}{l}\text { Computer modelling } \\
\text { Compugen Simpheny } \\
\text { Genomatica Accelerys } \\
\\
\text { Virtual patients } \\
\text { (Physiome and } \\
\text { Physiolab) }\end{array}$ & $\begin{array}{l}\text { Models of human airways and vascular } \\
\text { branching, bronchoconstriction, } \\
\text { inflammation, physiology, interactions } \\
\text { between immune system and allergens } \\
\text { and metabolic pathways } \\
\text { Complex disease modelling is possible } \\
\text { Can reflect disease heterogeneity and } \\
\text { severity of disease } \\
\text { Fast and high-throughput methods } \\
\text { Hypothesis-driven research } \\
\text { Incorporates a variety of scientific fields }\end{array}$ & $\begin{array}{l}\text { Still relatively undeveloped, will } \\
\text { require large amounts of further } \\
\text { work } \\
\text { Requires wealth of data and } \\
\text { coordination of data sharing } \\
\text { Models require validation, (models } \\
\text { work on what is known, if the } \\
\text { mechanism is not clear then the } \\
\text { model might display errors) } \\
\text { Unknown challenges ahead }\end{array}$ & [136-150] \\
\hline $\begin{array}{l}\text { Genetic } \\
\text { studies }\end{array}$ & $\begin{array}{l}\text { Molecular phenotyping } \\
\text { Linkage analysis } \\
\text { Genetic mapping } \\
\text { Epigenetic studies } \\
\text { Microarray analysis }\end{array}$ & $\begin{array}{l}\text { Provides useful direction for further } \\
\text { research } \\
\text { Can examine and identify candidate genes } \\
\text { Possibility to study interaction of } \\
\text { environment and genetics with epigenetic } \\
\text { studies } \\
\text { Integration with systems biology provides } \\
\text { useful way to identify candidate genes and } \\
\text { microarrays can highlight potential markers }\end{array}$ & $\begin{array}{l}\text { Often difficult to interpret, to work } \\
\text { with and uncover Complex field } \\
\text { Undeveloped area for asthma } \\
\text { research } \\
\text { Used as a highlighting tool so far }\end{array}$ & [151-162] \\
\hline $\begin{array}{l}\text { Exploiting } \\
\text { available } \\
\text { data }\end{array}$ & $\begin{array}{l}\text { Patient data } \\
\text { Medical records }\end{array}$ & $\begin{array}{l}\text { Wealth of patient data available } \\
\text { Models of acute changes can be studied } \\
\text { over years } \\
\text { Medical records can be used to watch } \\
\text { trends }\end{array}$ & $\begin{array}{l}\text { Requires effort to integrate and } \\
\text { connect the networks of data } \\
\text { Requires patient collaboration }\end{array}$ & [163-168] \\
\hline
\end{tabular}




\section{In vitro cultures}

Owing to the inaccessibility of the bronchial system, human studies have historically been limited to bronchial biopsies and whole-lung tissue studies. However, with advances in cell culture techniques, opportunities to develop in vitro models relevant to asthma have emerged. In vitro models can use cells or respiratory tissue explants; the ease with which human cells can be accessed, isolated and purified from peripheral and cord blood and respiratory tissues or obtained from sputum, nasal or bronchial washings and biopsies, means that they can be cultured and analysed for phenotypic or genetic features. Lavage studies can generate human samples for ex vivo analysis and, more recently, radiologically guided bronchial brushings in patients with lung transplants have been performed to obtain small airway epithelial cells for the establishment of submerged cell cultures with direct translatability to asthma studies [110]. Evidence from in vitro cell culture work has suggested that the bronchial epithelium is fundamental to the development of allergic pathology and that the relationship between the bronchial epithelium, stem cells and the mesenchyme is crucial [111,112]. Therefore, mixed cultures of bronchial cells have great potential for testing therapeutic targets; indeed, one culture system of bronchial biopsy explants was developed successfully to gain insight into which cytokines are involved with perpetuating allergeninduced inflammatory processes in the asthmatic airway $[113,114]$.

Through the use of immune cells from healthy subjects and patients with asthma, both the adaptive [5154] and innate [115,116] immune responses can be analysed. Individual cell types, such as Th2 cells from blood and the respiratory tract, blood-derived eosinophils and antigen-presenting cells (APC) from peripheral blood mononuclear cells (PBMC), have been isolated to reveal properties specific to the allergic response of asthma (e.g. the discovery that specific allergens bring about degranulation and elastase release in neutrophils [117]). Using bone marrow-derived stem cells, which can differentiate into eosinophils, from patients with asthma and their offspring, might also shed light on the development of allergic disease [118]. The in vitro use of innate immune cells has been cited as a promising approach for elucidating disease pathogenesis and target identification [119]. The immunological nature of asthma necessitates a human-specific approach when designing experiments; therefore, the most reliable cell sources would be human derived, especially considering the immunological variations between species [67]. It has been speculated that new models of allergic asthma could evolve from in vitro research with differentiated stem cells provided by individuals [119].

The choice in in vitro studies between the use of primary cells and immortalised cell lines is an important one [120]. Although cell lines offer the advantage of a limitless supply of experimental substrate, which in some instances is amenable to chronic studies, concerns regarding the biological relevance of immortalised (usually cancer) cell lines and their potentially high variability are substantial. By contrast, primary cells offer clear advantages in terms of relevance to normal human biological activity, but also have their limitations, including donor variability and functions, such as cytokine secretion, being crucially dependent on the culture technique used [121]. However, human-derived primary cells appear to be the most appropriate for biologically relevant modelling of human disease. Early technological limits to the use of primary cells have been eased since advances in tissue engineering and the manufacture of biological scaffolds, so much so that BéruBé and colleagues used tissue-engineered primary cells as in vitro trachea-bronchial constructs for inhalation toxicology, predicting the efficacy and toxicity of drugs [122]. The study of human bronchial epithelium was made possible by the production of human bioengineered bronchial tissue equivalents [114]. Bronchial epithelial cells and fibroblasts taken from biopsies from healthy subjects and patients with asthma can be cultured on a mesenchymal layer and will undergo differentiation into ciliated goblet cells in a stratified epithelium mimicking the human bronchi. This model can offer insights into physiological and pathophysiological responses of the bronchial epithelium and the intricate interactions between the allergic response of asthma and the respiratory tract. 
Often seen as a viable alternative to animal experimentation, cell and tissue culture systems are indispensable in biomedical research. Tissue engineering, however, offers a functional approach to disease research, whereby organised frameworks of cell types provide a network of interactions exhibiting original characteristics occurring on a small or large scale. At a 3D level, the interplay among cell signals, soluble factors and physical forces within a cellular environment can be captured. The standardisation of such environments can be difficult and prior knowledge of the immune response and cellular interplay is required to create effective experiments [3]. There are now several in vitro models available, most of which focus on the bronchial epithelium owing to the numerous pathologies associated with this region. These models exhibit complex characteristics afforded by advances, such as synthetic biomatrix development, bioreactors for culture inserts and quantitative cell viability tests. Primary cells for these cultures can be obtained from several sources: patient donations after surgery or postmortem tissues [normal human bronchial epithelium (NHBE), Mattek EpiAirway ${ }^{T M}$ or Epithelix MucilAir ${ }^{T M}$ ], cells generated from cancerous tissues (calu-3), and primary cells trans-formed by viruses (BEAS-2B or 16HBE140-) [123].

The most commonly used stand-alone model is NHBE tissue grown in an air-liquid interface (ALI). For example, the MucilAir ${ }^{\mathrm{TM}}$ construct incorporates basal, goblet and active ciliated cells, mucus, active ion transport, metabolic activity and a range of chemokines and cytokines, functional for more than a year. The increased availability of oxygen at the ALI surface, compared with that of the submerged culture, causes epithelial cells to exhibit an increase in ciliation, recapitulating the in vivo-like surface phenotype. This makes ALI cultured models useful for deposition experiments on the lung surface, which can then be further examined using proteomic, morphological analysis and toxicogenomic tech-niques [124]. The longevity of NHBE cells enables acute, chronic and repeat studies to be carried out. It is now also possible for researchers to create an in-house human tissue-equivalent using medical waste from human tissue banks or companies and expanding them for their own use. Advantages of these systems include low maintenance costs, ease of handling and of deriving materials for analysis. MucilAir is not only morphologically and function-ally differentiated, but it can also be maintained in a homeostatic state for more than a year [125]. This makes it possible to study the initial and chronic aspects of asthma disease and the interaction between different cell types, the elucidation of genetic determinants of the disease and drug-screening possibilities.

3D cell culture constructs have developed rapidly over the past few years into accurate and advanced models of disease states and present interesting possibilities if developed further to enable them to mimic a broader association of the key players in asthma. A 3D tissue construct using three distinct primary human cell types, human umbilical vein endothelial cells (HUVECs), normal human bronchial epithelial cells and fibroblasts (NHBE/Fs), was cultivated on a fibrin gel with soluble mediators and an ALI for the NHBE cells, and was successfully characterised and validated as a model of human airway mucosa. The model was used to examine cell-cell synergistic interactions [126]. Similarly, Tomei and col-leagues developed a 3D model that, at 21 days, exhibited a pseudostratified epithelium comprising basal cells, mucus-secreting cells and ciliated columnar cells with beating cilia. Using micro-particle tracking, the investigators were able to observe transport between groups of cells and, coupled with immunostaining, tight junction loss after mechanical stress was observed. The model was well defined, reproducible and controllable, making this a powerful tool for asthma research [127].

The development of advanced in vitro systems and their integration with other methodologies maximises the usability of resulting models and the information that can be obtained. Researchers incorporated atomic force microscopy in a study looking at spreading and migration of cells to determine the effect of corticosteroids on epithelial cell wound repair [128]. Similarly, Persoz and colleagues designed and adapted an in vitro model using a direct exposure device for studying lung epithelial cells to under-stand 
the effects of air pollutants suspected of exacerbating asthma. Their model demonstrated the feasibility and sensitivity of the exposure system for testing inflammatory cellular effects of gases at environmental doses directly on human respiratory cells [129]. Extending the integration of methodologies beyond disciplines and incorporating the skills and techniques of other scientific fields will not only offer the means to answer outstanding questions, but potentially offer scope for connecting asthma research angles, thus creating a more innovative research field. Currently, cellular in vitro assays do not model the complexity of the disease sufficiently in contrast to tissue explant models (Table 1).

\section{Human tissue and organ explants}

Despite the fragility of the lung, it is possible to culture human organ explants under perfusion conditions. Using human tissue explants as models of allergic asthma offers a clear advantage over cell cultures in that the structure and the microenvironment within the tissue is maintained. Therefore, it is possible to monitor the interactions of the cells with this environment, and measurements of mucus production and bronchial constriction can be made, together with an assessment of cell functions through bronchial cell chemokine [130] and cytokine production, and inflammatory effects on epithelium [131].

Results obtained from donor models of this kind have been disparate between different patients, indicating the differences in pathophysiology and the importance of determining the predictivity of the model. Taking the use of explants a stage further, precision-cut lung slices maintained in patient serum are also a valuable tool when coupled with video microscopy to record the bronchoconstriction process [132]. Khan and colleagues used lung explants to investigate the effects of enzymatic digestion on the rate of airway narrowing. Corroboration of their results was performed using a computational model [133]. Additionally, bronchial rings have been maintained after surgical procedures to explore allergen challenge [134]. The availability of intact tissues from the relevant species is desirable from the standpoint of biological relevance; however, it is recognised that the limited accessibility and short lifetime of human primary tissue samples impose major limitations on this avenue of research. Only a limited number of approaches are currently ethically acceptable and humans usually have the disease before they are studied, which renders dynamic studies of asthma development and dis-ease control difficult, but not impossible if one considers occupational asthma [13]. Lung tissue models require bronchial biopsy, which although safe, is not a trivial process [135]. However, the lack of availability and practicality issues surrounding the use of human tissues would benefit from the expansion of human organ and tissue banks and would be a direct benefit to research [132].

\section{In silico modelling: virtual patients}

The advent of in silico technologies has yet to penetrate the asthma research field fully; nevertheless, it represents the newest wave of modelling technology in asthma research. Computer models of human airways and vascular branching can take into account spatial arrangements of the airways, allowing for the study of bronchoconstriction [136], inflammation of the airway wall, inter-actions between aeroallergens and the immune system [137], the links between airway narrowing and the functional effects of airway remodelling [138], thickening of the mucus layer and effects of disease on deposition of inhaled particles [139]. This methodology is simple and accurate to use and is more relevant than any animal species in reproducing human lung airway behaviour, as illustrated through experimental validation [140]. The comparability of human lungs to anatomically accurate computer models was demonstrated when a wedged bronchoscope using human subject data was found to be similar, thereby corroborating the use of this model. When it comes to the deeper mechanisms of the lungs, for example cellular behaviour and the intricate path-ways, it will be interesting to see how computational models can contribute. Some systems, such as SimPheny, have been developed with this purpose in mind 
(GT Life Sciences; http://www.gtlifesciences.com/technology/Simpheny.html). Genoma-tica (http://www.genomatica.com) examines aspects of physiology and Compugen (http://www.cgen.com) models are able to predict protein-protein interactions based on experimental and clinical data. There are now projects focusing on the data collation and building the bioinformatics databases needed to make the models, such as Accelerys (http://www.accelrys.com). Mathematical descriptions of the changes in human lungs produced by asthma have been developed and reflect the heterogeneity and severity of the disease. Mathematical modelling using basic fluid dynamics to characterise airway resistance has been applied to examine the effects of airway smooth muscle shortening and thickening on changes in pulmonary resistance. Use of this technique has shown that muscle mass is the most probable abnormality responsible for increased resistance observed in asthma [141]. Similarly, airway narrowing [142] and mucosa integrity predictions have been made using other models [143].

In drug discovery, in silico screening for the identification of novel therapeutics is useful and is commonly where in silico methods tend to be placed. However, there is promise for many in silico techniques to also be exploited at the bench level, which would provide a direct transition to the clinic and drug trials, sidestepping the early involvement of animal models. The PRE-DICT model and algorithm were used as an in silico technique in drug discovery for G protein-coupled receptors (GCPRs), an important family of drug targets, without the requirement for structural information on receptors [144]. This type of highthroughput screening approach, although discussed in terms of drug discovery, is also a potential technique in basic research, given that the protein structure and the membrane environment are the only requirements for finding potential chemical binding partners, which can be human specific.

Perhaps the most promising of the in silico technologies is the 'virtual patient'. Initiated to reduce costs in bringing drugs to market, the virtual patient is also a suitable model to study pathophysiology mapped to patient data because simultaneously reflecting the patient variability. It therefore provides a major impetus for further development. Computer simulations have led to the generation of the 'virtual lung', a 3D model of a human respiratory tract that provides a physiologically relevant set of measurements of healthy and asthmatic lungs. Models can be built from several technologies, the most recent being single photon emission computed tomography (SPECT), high-resolution computed tomography (HRCT) and magnetic resonance imaging (MRI), with the latter being able to resolve the geometry of very small airways [145]. Virtual organs enable researchers to evaluate bronchoconstriction, inflammation and mucosal thickness, and have been used to predict the efficiency of aerosol drug delivery [146]. The role for these models in studying aerosol therapies is apparent from their proven ability to model particle transport, flow and deposition. Their continued application will facilitate the study of the fate of inhaled particles of a range of sizes and in different respiratory conditions for each individual specification [147], which has obvious advantages at the bench. Additionally, the morphological model could facilitate the development of methods for validating computational fluid dynamics studies with SPECT data. The virtual modelling procedure is fast, low cost (many of the software programs are free), and human and patient specific. The models depend on accurate MR/SPECT/HRCT images, which are readily available.

The 'Physiome' project (http://www.physiome.com) embodies the concept of integrative biology; it provides a quantitative and integrated description of the physiological state of an individual or species in terms of function, which is built on information (genomic, proteomic and morphometric) and structure. At the smallest level, it incorporates details on cell biochemistry, endocrinology and systems up to organs, and looks at genome and gene regulation in connection with the functional behaviour of the organism. There are several models from which to choose, including lungs, which promote the use of comprehensive data-bases of information already available and an integrative and analytical approach to studying disease. It is essential to make use of all relevant and reliable existing data, which will provide a useful basis for comparison to the human system and aid in minimising de novo animal use. A model can 
only be as accurate as the data upon which it is based, so pools of robust data must be available. Researchers working on the Physiome project state that this is only the very beginning, and many challenges lie ahead, such as linking the models to clinical data and to the standard image formats widely used in clinical imaging devices, such as MRI, and applying the physiome to genotype-phenotype questions [148].

Using the 3D arbitrary Lagrangian-Eulerian (ALE)-based fluid-structure interaction (FSI) method, researchers investigated respiratory flow in a human virtual airway bifurcation with rigid and compliant walls. This airway model is a realistic model based on multi-detector computed tomography (MDCT) data demonstrating the importance of airway wall motion in influencing airway flow patterns [149]. US-based Entelos Inc. (http://www.entelos.com/index.php) is developing mechanistic mathematical models of human disease, including asthma, using their patented PhysioLab1 technology. The models can be used in early target information studies through to Phase IV clinical trials based on the framework that integrates genomic, proteomic, physiological and environmental information in the context of the disease. Specific patient scenarios can be generated and drug solutions trialled and the application of this system at the basic research level as a tool for modelling disease progression warrants further exploration. Using genomic- and proteomic-based technologies at this level, as well as in drug discovery, can provide useful information; yet they often fail when trying to expand to the bigger picture (i.e. how these potential targets are regulated or their wider role in disease states). This is where in silico technology, such as the PhysioLab technology model, can add value, by using a top-down approach, relating clinical outcomes to disease specificities and to human biology and physiology. In a hypothetical research strategy, following creation of a virtual patient, hypotheses regarding gene function can be generated and tested through simulation of the human response and subsequently validated through in vitro experimentation.

If the development of computational processing potential fol-lows Moore's law of doubling every 18-24 months, in silico repre-sentations will be available to identify physical manifestations of disease very soon [150]. To understand the complexity of biolo-gical processes, the in silico approach enables rapid integration of new data and knowledge. It cannot be forgotten that computa-tional models do require experimental validation and, therefore, might simply have a role in providing insights for further research. Models can only be as accurate as the databases from which they are derived [135]. Additionally, the complexity, at the biological level, of in silico models are less predictive at the organ and organism level [74]. Regardless, it is no surprise that mathematical models are being heralded as a key to comprehension of complex diseases; using a computational approach is paramount to unra-velling the vast amounts of detailed data at an organ level [137].

\section{Genetic studies}

The concept of a universal 'asthma gene' is implausible, but there is no doubt that understanding the genetics of asthma will lead to improvements in its diagnosis, prevention and treatment. Several candidate genes with functional phenotypes involved in asthma have already been discovered [151], and molecular phenotyping has an important role in the future of asthma research [58] and in directing basic research trends.

Asthma is a complex inflammatory disorder whereby development is thought to be influenced by both genetic and environ- mental factors. In asthma, the complexity of these interactions is such that the genetic roots of this disease are difficult to uncover and interpret but represent the basis of why the disease occurs in one person and not another. Linkage analysis makes use of poly-morphic markers throughout the genome to determine affected patients in families [152], and analysis of inheritance patterns in families and twins has enabled some genetic-pathogenic linkages to be identified in bronchial 
asthma [153]. Numerous studies have examined candidate genes for associated disease and genetic variation; a complex task when considering the number of asthma-associated traits available, such as AHR, elevated IgE, atopy and airway remodelling. Genetic mapping studies have enabled genes of interest to be identified [154], and linkage disequilibrium studies can identify polymorphisms with disease associations. For example, the ADAM33 gene is thought to have a role in airway remodelling [155]. It is common for genetic studies to progress into transgenic studies using animal models once candidate genes are identified to investigate their contribution to pathophysiology. This must take into account the complex interplay between environmental factors and genetic traits and the experimental contradictions that can ensue [156]. Sidestep- ping the transgenic model in favour of a more human-relevant model might see the significance of genetic factors appear more readily.

Epigenetic changes, such as DNA methylation, histone modifications, miRNA changes and chromatin alterations after environmental exposures, are thought to be behind the variable incidence and remission of symptoms in asthma. Therefore, scientists have suggested that the study of environmental epigenetics holds immense promise in understanding a theoretically preventable disease [157]. Cohort-driven epigenetic research has the potential to answer many genetic questions; longitudinal studies featuring repeated measures of environmental exposures, collection of biological specimens over time and clinical outcome assessments could add a wealth of information on specific environmental pressure points and crucial windows of susceptibility. Used in conjunction with global screening methods, such as restriction fingerprinting, restriction landmark genomic scanning, methylation of CpG island amplificationrepresentational difference analysis and methylation target microarrays, to identify candidate regions as well as to reassess genes of interest, epigenomes susceptible to environmentally induced asthma could be identified in the future [158]. Although there are many perplexing factors that will limit the ability to study epigenetic pathways, there is still great promise in this field [157].

The integration of systems biology and bioinformatics is an exploratory approach to investigating asthma genetics, according to which mathematical models are used to identify crucial asthma-related candidate genes, the functions of which are then con-firmed by biological procedures and tested using biological samples from different human populations and races. This strategy is an example of an integrated approach, whereby research costs are reduced and research efficiency is increased. The KEGGPATHWAY database (KEGG Pathway Database; http://www.genome.ad.jp/kegg/pathway.html) is one such strategy consisting of many net-work maps of interactions between ligands and receptors in the immunological system associated with asthma. This network map can be disassembled for analysis, including the T-cell signalling pathway, where candidate genes are analysed and confirmed through highthroughput biological methods, such as resequencing and genotyping [159].

Use of the microarray technology platform combined with in vitro experimental approaches is another approach to the identification of disease-associated genes. For example, human bronchial epithelial cultures were probed for genes regulated by IL-4 and IL-13 and, through comparison with cDNA libraries, several disease-associated genes have been identified. In combination with in vitro techniques [160], the results were successfully corroborated [161]. There is a great need for bio-markers to become an integral part of drug discovery and development. Microarray analysis provides a unique approach in profiling the entire genome, offering insight into potential markers and thereby representing a vital tool for basic research [162].

\section{Exploiting available data: human models and/or patient studies}

Clinical studies using volunteer patients [163] and their biological samples $[160,164]$ are reasonably common, but they could be better integrated into research strategies. The initiation of the Severe Asthma 
Research Program (SARP) in the USA in 2000 was the first step toward recognising the need for networking to address severe asthma characteristics. Patient data are shared across eight centres and, since its establishment, SARP has pro-vided the numbers of subjects and depth of analysis required to elucidate mechanisms underlying many phenotypes [165]. Through the engagement of asthmatic patient volunteers, it has been possible to induce acute changes through controlled allergen challenge in a clinic, an approach used for many years to study mechanisms of asthma in affected individuals [166]. A human model of asthma exacerbation was also used to observe allergen inhalation challenge in patients with asthma successfully to give insights into inflammatory mediator interplay and development of new drug targets [167]. A less obvious use of patient data is in the wider use of electronic medical records for clinical research, whereby investigators create a predictive model of chronic asthma using demographic and co-morbidity data extracted from the 'asthma data mart' created by the US National Centre for Biomedical Computing [168]. Bayesian networks were used to create a predictive and accurate model with the potential to better under-stand disease trends in the future and inform basic medical research.

\section{Concluding remarks}

Unlike in regulatory testing, a common infrastructure for using 3Rs methods in basic research is rare. Notwithstanding achievements made to date in the treatment of asthma, the relevance of artificial animal models is considered to be overestimated in many cases, which could be contributing to the current disease research climate (i.e. sufficient research but insufficient progress). With animal research, some fundamental issues are often overlooked, such as species-dependent differences, limitations of extrapolating data from animals to humans, lack of validation of animal methods, underreporting of pitfalls and limitations of models and statistical under-powering of data. There is a lack of visibility of 3Rs approaches and, until there is an appreciation of the value-added of these 21st-century tools and technologies, such methods will not become an integral part of research. The benefits of expanding the use of in vitro and computational approaches include lower cost, higher throughput, increased replicates, simplicity, improved accessibility, reduction of variation and the use of human materials, all of which have the strong potential to lead to more human-relevant research findings. Despite the ever-increasing sophistication of in vitro and in silico tools and models, relatively few are being exploited to their full potential in the basic research arena.

Laboratories often use different methods and protocols when researching common themes, making data comparison difficult. It is also common for application of an alternative method to rarely extend beyond the confines of the laboratory that invented it, without good reason. The models mentioned in this review have their strengths and weaknesses, largely depending on the goal and application of research. Despite the use of animal models and their ability to simulate some of the symptoms of asthma, the disadvantages surrounding their use and the slow progress in this field brings to light the need to move away from the historical paradigm and toward greater integration of 21st-century methodologies. Models are an essential part of basic research; the use of 3D in vitro cell models of human airways not only provides a powerful tool to deepen the knowledge already obtained on human asthma, but also represents an ideal means for screening and identifying potential drug targets. There is also a wealth of experimental data waiting to be used for method validation. The development of further tissueengineered, in vitro pulmonary equivalents is a promising way to reduce animal use in inhalation research. It is undeniable that reliance on animal models might continue simultaneously as the field begins to accept the benefits and robustness of non-animal approaches and as such methods develop, but this strategised process of reduction will hopefully lead to replacement in many areas. There is also an urgent need for further research integrating in vitro and in silico approaches, together with multidisciplinary programs, to foster cross-talk and synergies among scientific disciplines. A multidisciplinary approach, integrating a broad range of techniques from 3D cell cultures to mathematical models and 
using human patient data following a targeted and mapped out strategy, would not only reduce reliance on animals, but would also create a more scientifically robust asthma research field with a potentially more streamlined translation of research results from the bench to the clinic.

\section{Acknowledgement}

The author would like to thank Troy Seidle and Gill Langley for their reviews of this manuscript.

\section{References}

1. Broide, D.H. et al. (2011) Advances in mechanisms of asthma, allergy, and immunology in 2010. J. Allergy Clin. Immunol. 127, 689-695

2. Kelly, F.J. and Fussell, J.C. (2011) Air pollution and airway disease. Clin. Exp. Allergy 10.1111/j.1365-2222.2011.03776.x

3. Zosky, G.R. and Sly, P.D. (2007) Animal models of asthma. Clin. Exp. Allergy 37, 973-988

4. Persson, C.G. (2002) Con: mice are not a good model of human airway disease. Am. J. Respir. Crit. Care Med. 166, 6-7

5. Laitinen, L.A. et al. (1985) Damage of the airway epithelium and bronchial reactivity in patients with asthma. Am. Rev. Respir. Dis 131, 599-606

6. Redman, T.K. et al. (2001) Pulmonary immunity to ragweed in a beagle dog model of allergic asthma. Exp. Lung Res. 27, 433-451

7. Semko, C.M. et al. (2011) Discovery of a potent, orally bioavailable pyrimidine VLA-4 antagonist effective in a sheep asthma model. Bioorg. Med. Chem. Lett. 21, 1741-1743

8. Capitanio, J.P. et al. (2011) Behavioral inhibition is associated with airway hyperresponsiveness but not atopy in a monkey model of asthma. Psychosom. Med. 73, 288-294

9. Dahlin, J.S. et al. (2011) IgE immune complexes stimulate an increase in lung mast cell progenitors in a mouse model of allergic airway inflammation. PloS ONE 10.1371/journal.pone.0020261

10. Liu, J. et al. (2011) PPARg agonist rosiglitazone prevents perinatal nicotine exposure-induced asthma in rat offspring. Am. J. Physiol. Lung Cell Mol. Physiol. 300, L710-L717

11. Lee-Fowler, T.M. et al. (2009) Comparison of intradermal skin testing (IDST) and serum allergenspecific IgE determination in an experimental model of feline asthma. Vet. Immunol. Immunopathol. $132,46-52$

12. Gibbons, A. et al. (2011) The effect of liposome encapsulation on the pharmacokinetics of recombinant secretory leukocyte protease inhibitor (RSLPI) therapy after local delivery to a guinea pig asthma model. Pharmaceut. Res. 1-13

13. Wenzel, S. and Holgate, S.T. (2006) The mouse trap: it still yields few answers in asthma. Am. J. Respir. Crit. Care Med. 174, 1173-1176

14. Sylvin, H. et al. (2002) The tryptase inhibitor apc-366 reduces the acute airway response to allergen in pigs sensitized to Ascaris suum. Clin. Exp. Allergy 32, 967- 971

15. Ramsay, C.F. et al. (2011) Oral montelukast in acute asthma exacerbations: a randomised, doubleblind, placebo-controlled trial. Thorax 66, 7-11

16. Mauser, P. et al. (1995) Effects of an antibody to interleukin-5 in a monkey model of asthma. Am. J. Respir. Crit. Care Med. 152, 467-472

17. Mosmann, T. et al. (1986) Two types of murine helper t cell clone. I. Definition according to profiles of lymphokine activities and secreted proteins. J. Immunol. 136, 2348-2357

18. Taube, C. et al. (2004) Insights into the pathogenesis of asthma utilizing murine models. Int. Arch. Allergy Immunol. 135, 173-186

19. Reinero, C.R. et al. (2009) Asthma in humans and cats: is there a common sensitivity to aeroallegens in shared environments? Environ. Res. 109, 634-640 
20. Deaton, C. (2006) The role of oxidative stress in an equine model of human asthma. Redox Report $11,46-52$

21. Szelenyi, I. (2000) Animal models of bronchial asthma. Inflamm. Res. 49, 639- 654

22. Zosky, G.R. et al. (2004) The pattern of methacholine responsiveness in mice is dependent on antigen challenge dose. Respir. Res. 5, 15

23. Hylkema, M.N. et al. (2002) The strength of the ova-induced airway inflammation in rats is strain dependent. Clin. Exp. Immunol. 129, 390-396

24. Smith, N. and Johnson, F.J. (2005) Early- and late-phase bronchoconstriction, airway hyperreactivity and cell influx into the lungs, after 50-adenosine monophosphate inhalation: comparison with ovalbumin. Clin. Exp. Allergy 35, 522-530

25. Kips, J.C. et al. (2003) Murine models of asthma. Eur. Respir. J. 22, 374-382

26. Shinagawa, K. and Kojima, M. (2003) Mouse model of airway remodeling: strain differences. Am. J. Respir. Crit. Care Med. 168, 959-967

27. Rajagopalan, G. et al. (2011) Hla-dr polymorphism modulates response to house dust mites in a transgenic mouse model of airway inflammation. Tissue Antigens 77, 589-592

28. Vaickus, L. et al. (2010) Inbred and outbred mice have equivalent variability in a cockroach allergen-induced model of asthma. Comp. Med. 60, 420-426

29. Samarasinghe, A.E. et al. (2011) A comparison between intratracheal and inhalation delivery of Aspergillus fumigatus conidia in the development of fungal allergic asthma in c57bl/6 mice. Fungal Biol. 115, 21-29

30. Nemeth, K. et al. (2010) Bone marrow stromal cells use TGF-beta to suppress allergic responses in a mouse model of ragweed-induced asthma. Proc. Natl. Acad. Sci. U. S. A. 107, 5652-5657

31. Nikota, J. et al. (2011) Differential expression and function of breast regression protein 39 (brp-39) in murine models of subacute cigarette smoke exposure and allergic airway inflammation. Respir. Res. 12, 39

32. Kelada, S.N.P. et al. (2011) Strain-dependent genomic factors affect allergen-induced airway hyper-responsiveness in mice. Am. J. Respir. Cell Mol. Biol. 10.1165/ rcmb.OC

33. Bilenki, L. et al. (2010) Dendritic cells from mycobacteria-infected mice inhibits established allergic airway inflammatory responses to ragweed via IL-10- and IL- 12-secreting mechanisms. J. Immunol. 184, 7288-7296

34. Wenzel, S. and Holgate, S.T. (2006) The mouse trap: it still yields few answers in asthma. Am. J. Respir. Crit. Care Med. 174, 1173-1176 discussion 1176-1178

35. Coffman, R.L. and Hessel, E.M. (2005) Nonhuman primate models of asthma. J. Exp. Med. 201, 1875-1879

36. Repa, A. et al. (2004) Influence of the route of sensitization on local and systemic immune responses in a murine model of type i allergy. Clin. Exp. Immunol. 137, 12- 18

37. Corrigan, C.J. et al. (1988) T lymphocyte activation in acute severe asthma Lancet 331, 1129-1132

38. Whitehead, G.S. et al. (2003) Allergen-induced airway disease is mouse strain dependent. Am. J. Physiol. Lung Cell Mol. Physiol. 285, L32-L42

39. Shirai, N. and Geoly, F.J. (2010) Eosinophilic airway inflammation in a cynomolgus monkey. Vet. Pathol. 47, 318-321

40. Plopper, C.G. and Hyde, D.M. (2008) The non-human primate as a model for studying COPD and asthma. Pulm. Pharmacol. Ther. 21, 755-766

41. Allen, J.E. et al. (2009) Animal models of airway inflammation and airway smooth muscle remodelling in asthma. Pulm. Pharmacol. Ther. 22, 455-465

42. Elenkov, I.J. and Chrousos, G.P. (1999) Stress hormones, Th1/Th2 patterns, pro/ anti-inflammatory cytokines and susceptibility to disease. Trends Endocrinol. Metab. 10, 359-368

43. Takayama, G. et al. (2006) Periostin: a novel component of subepithelial fibrosis of bronchial asthma downstream of IL-4 and IL-13 signals. J. Allergy Clin. Immunol. 118, 98-104 
44. Tang, M.L. et al. (2006) Airway remodelling in asthma: current understanding and implications for future therapies. Pharmacol. Ther. 112, 474-488

45. Rose, M.C. and Voynow, J.A. (2006) Respiratory tract mucin genes and mucin glycoproteins in health and disease. Physiol. Rev. 86, 245-278

46. Young, H.W. et al. (2006) A3 adenosine receptor signaling contributes to airway mucin secretion after allergen challenge. Am. J. Respir. Cell Mol. Biol. 35, 549- 558

47. James, A. (2005) Airway remodeling in asthma. Curr.Opin. Pulm. Med. 11, 1-6

48. Elias, J.A. et al. (1999) Airway remodeling in asthma. J. Clin. Invest. 104, 1001- 1006

49. Kumar, R.K. and Foster, P.S. (2002) Modeling allergic asthma in mice: pitfalls and opportunities. Am. J. Respir. Cell Mol. Biol. 27, 267-272

50. Strickland, D.H. et al. (2006) Reversal of airway hyperresponsiveness by induction of airway mucosal CD4+CD25+ regulatory T cells. J. Exp. Med. 203, 2649-2660

51. Tigani, B. et al. (2007) Lung inflammation and vascular remodeling after repeated allergen challenge detected noninvasively by MRI. Am. J. Physiol. Lung Cell. Mol. Physiol. 292, L644-L653

52. Labonté, I. et al. (2009) The effects of repeated allergen challenge on airway smooth muscle structural and molecular remodeling in a rat model of allergic asthma. Am. J. Physiol. Lung Cell. Mol. Physiol. 297, L698-L705

53. Karaman, M. et al. (2011) Effects of curcumin on lung histopathology and fungal burden in a mouse model of chronic asthma and oropharyngeal candidiasis. Arch. Med. Res. 42, 79-87

54. de Weck, A.L. et al. (1997) Dog allergy, a model for allergy genetics. Int. Arch. Allergy Immunol. $113,55-57$

55. Van der Velden, J. and Snibson, K.J. (2011) Airway disease: the use of large animal models for drug discovery. Pulm. Pharmacol. Ther. DOI: 10.1016/ j.pupt.2011.02.001

56. Tsuchiya, K. et al. (2010) EGF receptor activation during allergic sensitization affects IL-6-induced T-cell influx to airways in a rat model of asthma. Eur. J. Immunol. 40, 1590-1602

57. Ayanoglu, G. et al. (2011) Modelling asthma in macaques: longitudinal changes in cellular and molecular markers. Eur. Respir. J. 37, 541-552

58. Ober, C. and Hoffjan, S. (2006) Asthma genetics 2006: the long and winding road to gene discovery. Genes Immun. 7, 95-100

59. Huovinen, E. et al. (2003) Factors associated to lifestyle and risk of adult onset asthma. Respir. Med. 97, 273-280

60. Gern, J.E. et al. (1999) Early life origins of asthma. J. Clin. Invest. 104, 837-843

61. Holt, P.G. and Sly, P.D. (2002) Interactions between RSV infection, asthma, and atopy: unraveling the complexities. J. Exp. Med. 196, 1271-1275

62. Illi, S. et al. (2006) Perennial allergen sensitisation early in life and chronic asthma in children: a birth cohort study. Lancet 368, 763-770

63. Celedon, J.C. et al. (2002) Exposure to cat allergen, maternal history of asthma, and wheezing in first 5 years of life. Lancet 360, 781-782

64. Schaub, B. et al. (2006) The many faces of the hygiene hypothesis. J. Allergy Clin. Immunol. 117, 969-977

65. Holt, P.G. et al. (2005) Contemporaneous maturation of immunologic and respiratory functions during early childhood: implications for development of asthma prevention strategies. J. Allergy Clin. Immunol. 116, 16-24

66. Siegle, J. et al. (2010) Early-life viral infection and allergen exposure interact to induce an asthmatic phenotype in mice. Respir. Res 11, 14

67. Mestas, J. and Hughes, C.C. (2004) Of mice and not men: differences between mouse and human immunology. J. Immunol. 172, 2731-2738

68. Malm-Erjefalt, M. et al. (2001) Degranulation status of airway tissue eosinophils in mouse models of allergic airway inflammation. Am. J. Respir. Cell Mol. Biol. 24, 352- 359 
69. Kaviratne, M. et al. (2004) IL-13 activates a mechanism of tissue fibrosis that is completely TGF-b independent. J. Immunol. 173, 4020-4029

70. Wenzel, S.E. et al. (2002) TGF-beta and IL-13 synergistically increase eotaxin-1 production in human airway fibroblasts. J. Immunol. 169, 4613-4619

71. Bosse, Y. and Rola-Pleszczynski, M. (2007) Controversy surrounding the increased expression of tgfbeta1 in asthma. Respir. Res. 8, 66

72. Perkins, C. et al. (2011) Selective stimulation of il-4 receptor on smooth muscle induces airway hyperresponsiveness in mice. J. Exp. Med. 208, 853-867

73. Lee, G.R. and Flavell, R.A. (2004) Transgenic mice which overproduce th2 cytokines develop spontaneous atopic dermatitis and asthma. Int. Immunol. 16, 1155-1160

74. Walsh, E.R. et al. (2011) Computational and experimental analysis reveals a requirement for eosinophil-derived il-13 for the development of allergic airway responses in c57bl/6 mice. J. Immunol. 186, 2936-2949

75. Hirata, H. et al. (2011) Over-expression of the Itc4 synthase gene in mice reproduces human aspirin-induced asthma. Clin. Exp. Allergy 41, 1133-1142

76. Borish, L.C. et al. (1999) Interleukin-4 receptor in moderate atopic asthma. A phase I/II randomized, placebo-controlled trial. Am. J. Respir. Crit. Care Med. 160, 1816- 1823

77. Leckie, M.J. et al. (2000) Effects of an interleukin-5 blocking monoclonal antibody on eosinophils, airway hyper-responsiveness, and the late asthmatic response. Lancet 356, 2144-2148

78. Norris, V. et al. (2005) Effect of ivl745, a VLA-4 antagonist, on allergen-induced bronchoconstriction in patients with asthma. J. Allergy Clin. Immunol. 116, 761- 767

79. Tumas, D.B. et al. (2001) Anti-ige efficacy in murine asthma models is dependent on the method of allergen sensitization. J. Allergy Clin. Immunol. 107, 1025-1033

80. Lloyd, C.M. and Robinson, D.S. (2007) Allergen-induced airway remodelling. Eur. Respir. J. 29, 1020-1032

81. Brusasco, V. and Pellegrino, R. (2003) Complexity of factors modulating airway narrowing in vivo: relevance to assessment of airway hyperresponsiveness. J. Appl. Physiol. 95, 1305-1313

82. Al-Muhsen, S. et al. (2011) Remodeling in asthma. J. Allergy Clin. Immunol. 10.1016/j.jaci.2011.04.047

83. Zaias, J. et al. (2011) Repeated exposure to aerosolized brevetoxin-3 induces prolonged airway hyperresponsiveness and lung inflammation in sheep. Inhal. Toxicol. 23, 205-211

84. Hirota, J.A. et al. (2011) Modeling asthma in mice: what have we learned about the airway epithelium? Am. J. Respir. Cell Mol. Biol. 44, 431-438

85. Van Scott, M.R. et al. (2004) Dust mite-induced asthma in cynomolgus monkeys. J. Appl. Physiol. 96, 1433-1444

86. Johnson, L.R. and Vernau, W. (2011) Bronchoscopic findings in 48 cats with spontaneous lower respiratory tract disease (2002-2009). J. Vet. Intern. Med. 25, 236-243

87. Rydell-Tormanen, K. et al. (2008) Remodeling of extra-bronchial lung vasculature following allergic airway inflammation. Respir. Res. 9, 18

88. Holgate, S.T. (2011) The sentinel role of the airway epithelium in asthma pathogenesis. Immunol. Rev. 242, 205-219

89. Bettinelli, D. et al. (2002) Effect of gravity and posture on lung mechanics. J. Appl. Physiol. 93, 2044-2052

90. Bettinelli, D. et al. (2002) Effect of gravity on chest wall mechanics. J. Appl. Physiol. 92, 709-716

91. Schlesinger, R.B. and McFadden, L.A. (1981) Comparative morphometry of the upper bronchial tree in six mammalian species. Anat. Rec. 199, 99-108

92. Plopper, C.G. et al. (1983) Structure as revealed by airway dissection. A comparison of mammalian lungs. Am. Rev. Respir. Dis. 128, S4-S7 
93. Wright, J.L. and Churg, A. (2008) Animal models of copd: barriers, successes, and challenges. Pulm. Pharmacol. Ther. 21, 696-698

94. Sutherland, M.A. et al. (2009) Acute stress affects the physiology and behavior of allergic mice. Physiol. Behav. 98, 281-287

95. Irvin, C. and Bates, J. (2003) Measuring the lung function in the mouse: the challenge of size. Respir. Res. 4, 4

96. Bates, J.H.T. and Irvin, C.G. (2003) Measuring lung function in mice: the phenotyping uncertainty principle. J. Appl. Physiol. 94, 1297-1306

97. Bates, J. et al. (2004) The use and misuse of penh in animal models of lung disease. Am. J. Respir. Cell. Mol. Biol. 31, 373-374

98. Borges, M.C. et al. (2011) Effect of allergen challenge under isoflurane and halothane anesthesia in hyperresponsiveness and inflammation in a murine model of allergic asthma. Am. J. Respir. Crit. Care Med. 183, A2882

99. Meeusen, E.N. et al. (2009) Sheep as a model species for the study and treatment of human asthma and other respiratory diseases. Drug Discov. Today 6, 101-106

100. Kirschvink, N. and Reinhold, P. (2008) Use of alternative animals as asthma models. Curr. Drug Targets 9, 470-484

101. Suzuki, R. and Freed, A. (2000) Heparin inhibits eicosanoid metabolism and hyperventilationinduced bronchoconstriction in dogs. Am. J. Respir. Crit. Care Med. 161, 1850-1854

102. Pillow, J. et al. (2001) Effects of gestation and antenatal steroid on airway and tissue mechanics in newborn lambs. Am. J. Respir. Crit. Care Med. 163, 1158-1163

103. Hyde, D.M. et al. (2006) Asthma: a comparison of animal models using stereological methods. Eur. Respir. Rev. 15, 122-135

104. Anon, (2010) Directive 2010/63/Eu of the European Parliament and of the Council of 22 September 2010 on the protection of animals used for scientific purposes. Official J. Eur. Union L276/33 33-79

105. Russell, W.M.S. and Burch, R.L. (1959) The Principles of Humane Experimental Technique. Methuen

106. Finotto, S. et al. (2002) Development of spontaneous airway changes consistent with human asthma in mice lacking t-bet. Science 295, 336-338

107. Herz, U. et al. (2004) Increased airway responsiveness, allergy-type-i skin responses and systemic anaphylaxis in a humanized-severe combined immuno-deficiency mouse model. Clin. Exp. Allergy $34,478-487$

108. Lee, J.J. et al. (2004) Defining a link with asthma in mice congenitally deficient in eosinophils. Science 305, 1773-1776

109. Meurs, H. et al. (2008) Airway hyperresponsiveness in asthma: lessons from in vitro model systems and animal models. Eur. Respir. J. 32, 487-502

110. Banerjee, B. et al. (2009) Successful establishment of primary small airway cell cultures in human lung transplantation. Respir. Res. 26, 99

111. Puddicombe, S.M. et al. (2003) Increased expression of p21(waf) cyclin-dependent kinase inhibitor in asthmatic bronchial epithelium. Am. J. Respir. Cell Mol. Biol. 28, 61-68

112. Puddicombe, S.M. et al. (2000) Involvement of the epidermal growth factor receptor in epithelial repair in asthma. FASEB J. 14, 1362-1374

113. Dent, G. et al. (2002) Differential roles of IL-16 and CD28/b7 costimulation in the generation of Tlymphocyte chemotactic activity in the bronchial mucosa of mild and moderate asthmatic individuals. J. Allergy Clin. Immunol. 110, 906-914

114. Lordan, J.L. et al. (2001) The role of CD28-b7 costimulation in allergen-induced cytokine release by bronchial mucosa from patients with moderately severe asthma. J. Allergy Clin. Immunol. 108, 976981 
115. Myrtek, D. et al. (2004) Expression of interleukin-13 receptor alpha 1-subunit on peripheral blood eosinophils is regulated by cytokines. Immunology $112,597-604$

116. Davoine, F. et al. (2004) Role and modulation of cd16 expression on eosinophils by cytokines and immune complexes. Int. Arch. Allergy Immunol. 134, 165-172

117. Monteseirin, J. et al. (2003) Specific allergens enhance elastase release in stimulated neutrophils from asthmatic patients. Int. Arch. Allergy Immunol. 131, 174-181

118. Hoffjan, S. et al. (2004) Genetic variation in immunoregulatory pathways and atopic phenotypes in infancy. J. Allergy Clin. Immunol. 113, 511-518

119. Epstein, M.M. (2004) Do mouse models of allergic asthma mimic clinical disease? Int. Arch. Allergy Immunol. 133, 84-100

120. Drexler, H.G. et al. (2003) False leukemia-lymphoma cell lines; an update on over 500 cell lines. Leukemia 17, 416-426

121. Kikuchi, T. et al. (2004) Differentiation-dependent responsiveness of bronchial epithelial cells to IL4/13 stimulation. Am. J. Physiol. Lung Cell Mol. Physiol. 287, L119-L126

122. BéruBé, K. et al. (2010) Human primary bronchial lung cell constructs: the new respiratory models. Toxicology 278, 311-318

123. Forbes, B. (2000) Human airway epithelial cell lines for in vitro drug transport and metabolism studies. Pharm. Sci. Technol. Today 3, 18-27

124. Sexton, K. et al. (2008) Genomic biomarkers of pulmonary exposure to tobacco smoke components. Pharmacogenet. Genomics 18, 853-860

125. Epstein, M.M. (2004) Modeling allergic asthma: from in vitro assays to virtual patients. Drug Discov. Today 1, 387-394

126. Thompson, H.G. et al. (2007) A three-dimensional in vitro model of angiogenesis in the airway mucosa. Pulm. Pharmacol. Ther. 20, 141-148

127. Tomei, A.A. et al. (2008) Effects of dynamic compression on lentiviral transduction in an in vitro airway wall model. Am. J. Physiol. Lung Cell Mol. Physiol. 294, L79-L86

128. Wagh, A.A. et al. (2008) Localized elasticity measured in epithelial cells migrating at a wound edge using atomic force microscopy. Am. J. Physiol. Lung Cell Mol. Physiol. 295, L54-L60

129. Persoz, C. et al. (2010) An in vitro model to evaluate the inflammatory response after gaseous formaldehyde exposure of lung epithelial cells. Toxicol. Lett. 195, 99- 105

130. Komiya, A. et al. (2003) Concerted expression of eotaxin-1, eotaxin-2, and eotaxin-3 in human bronchial epithelial cells. Cell Immunol. 225, 91-100

131. Shahana, S. et al. (2002) Effects of the cationic protein poly-l-arginine on airway epithelial cells in vitro. Mediators Inflamm. 11, 141-148

132. Wohlsen, A. et al. (2003) The early allergic response in small airways of human precision-cut lung slices. Eur. Respir. J. 21, 1024-1032

133. Khan, M.A. et al. (2010) Influence of airway wall stiffness and parenchymal tethering on the dynamics of bronchoconstriction. Am. J. Physiol. Lung Cell Mol. Physiol. 299, L98-L108

134. Rovati, G.E. et al. (2006) Cysteinyl-leukotrienes in the regulation of beta2- adrenoceptor function: an in vitro model of asthma. Respir. Res. 7, 103

135. Huang, S. et al. (2009) In vitro organ culture models of asthma. Drug Discov. Today 6, 137-144

136. Fabry, B. and Fredberg, J.J. (2007) Mechanotransduction, asthma, and airway smooth muscle. Drug Discov. Today 4, 131-137

137. Llop-Guevara, A. et al. (2008) In vivo-to-in silico iterations to investigate aeroallergen-host interactions. PLoS ONE 3, E2426

138. Kaminsky, D.A. et al. (2004) Oscillation mechanics of the human lung periphery in asthma. J. Appl. Physiol. 97, 1849-1858

139. Martonen, T. et al. (2003) In silico modeling of asthma. Adv. Drug Deliv. Rev. 55, 829-849 
140. Choi, J.I. and Kim, C.S. (2007) Mathematical analysis of particle deposition in human lungs: an improved single path transport model. Inhal. Toxicol. 19, 925- 939

141. Lambert, R.K. et al. (1993) Functional significance of increased airway smooth muscle in asthma and copd. J. Appl. Physiol. 74, 2771-2781

142. Seow, C.Y. et al. (2000) Airway narrowing and internal structural constraints. J. Appl. Physiol. 88, 527-533

143. Wiggs, B.R. et al. (1997) On the mechanism of mucosal folding in normal and asthmatic airways. J. Appl. Physiol. 83, 1814-1821

144. Becker, O.M. et al. (2004) G protein-coupled receptors: in silico drug discovery in 3d. Proc. Natl. Acad. Sci. U. S. A. 101, 11304-11309

145. Zrimec, T. and Wong, J.S. (2007) Improving computer aided disease detection using knowledge of disease appearance. Stud. Health Technol. Inform. 129, 1324- 1328

146. Sbirlea-Apiou, G. et al. (2004) Simulation of the regional manifestation of asthma. J. Pharm. Sci. 93, 1205-1216

147. Burton, R.T. et al. (2004) Computer reconstruction of a human lung boundary model from magnetic resonance images. Respir. Care 49, 180-185

148. Bassingthwaighte, J. et al. (2009) The cardiac physiome: perspectives for the future. Exp. Physiol. 94, 597-605

149. Xia, G. et al. (2010) Airway wall stiffening increases peak wall shear stress: a fluid-structure interaction study in rigid and compliant airways. Ann. Biomed. Eng. 38, 1836-1853

150. George, S.C. (2007) In silico modeling of respiratory structure, function, and disease. Drug Discov. Today 4, 123-124

151. Szalai, C. et al. (2008) Asthma from a pharmacogenomic point of view. Br. J. Pharmacol. 153, 1602-1614

152. Halapi, E. and Hakonarson, H. (2004) Recent development in genomic and proteomic research for asthma. Curr. Opin. Pulm. Med. 10, 22-30

153. Cookson, W.O. (2002) Asthma genetics. Chest 121, 7S-13S

154. Postma, D.S. et al. (1995) Genetic susceptibility to asthma - bronchial hyperresponsiveness coinherited with a major gene for atopy. New Engl. J. Med. 333, 894-900

155. Van Eerdewegh, P. et al. (2002) Association of the adam33 gene with asthma and bronchial hyperresponsiveness. Nature 418, 426-430

156. Drazen, J.M. et al. (1996) Sorting out the cytokines of asthma. J. Exp. Med. 183, 1-5

157. Miller, R.L. and Ho, S.M. (2008) Environmental epigenetics and asthma: current concepts and call for studies. Am. J. Respir. Crit. Care Med. 177, 567-573

158. Ho, S.M. and Tang, W.Y. (2007) Techniques used in studies of epigenome dysregulation due to aberrant DNA methylation: an emphasis on fetal-based adult diseases. Reprod. Toxicol. 23, 267282

159. Gu, M.L. et al. (2010) New insight into the genes susceptible to asthma. J. Asthma 47, 113-116

160. Koh, Y.I. and Shim, J.U. (2010) Association between sputum natural killer t cells and eosinophilic airway inflammation in human asthma. Int. Arch. Allergy Immunol. 153, 239-248

161. Yuyama, N. et al. (2002) Analysis of novel disease-related genes in bronchial asthma. Cytokine 19, 287-296

162. Syed, F. et al. (2007) Identification of interleukin-13 related biomarkers using peripheral blood mononuclear cells. Biomarkers 12, 414-423

163. Richards, D.B. et al. (2010) Treatment with a peroxisomal proliferator activated receptor gamma agonist has a modest effect in the allergen challenge model in asthma: a randomised controlled trial. Respir. Med. 104, 668-674

164. Hewson, C.A. et al. (2010) Rhinovirus induces muc5ac in a human infection model, and in vitro via nf-kb and EGFR pathways. Eur. Respir. J. 36, 1425-1435 
165. Wenzel, S.E. and Busse, W.W. (2007) Severe asthma: lessons from the severe asthma research program. J. Allergy Clin. Immunol. 119, 14-21

166. Phipps, S. et al. (2004) Acute allergen-induced airway remodeling in atopic asthma. Am. J. Respir. Cell Mol. Biol. 31, 626-632

167. Gauvreau, G.M. and Evans, M.Y. (2007) Allergen inhalation challenge: a human model of asthma exacerbation. Contrib. Microbiol. 14, 21-32

168. Himes, B.E. et al. (2009) Prediction of chronic obstructive pulmonary disease (COPD) in asthma patients using electronic medical records. J. Am. Med. Inform. Assoc. 16, 371-379 